Wright State University

CORE Scholar

$9-1-2002$

\title{
Characterization of Homoepitaxial p-Type ZnO Grown by Molecular Beam Epitaxy
}

\author{
David C. Look \\ Wright State University - Main Campus, david.look@wright.edu \\ D. C. Reynolds \\ C. W. Litton \\ R. L. Jones \\ D. B. Eason
}

See next page for additional authors

Follow this and additional works at: https://corescholar.libraries.wright.edu/physics

Part of the Physics Commons

\section{Repository Citation}

Look, D. C., Reynolds, D. C., Litton, C. W., Jones, R. L., Eason, D. B., \& Cantwell, G. (2002). Characterization of Homoepitaxial p-Type ZnO Grown by Molecular Beam Epitaxy. Applied Physics Letters, 81 (10), 1830-1832.

https://corescholar.libraries.wright.edu/physics/79

This Article is brought to you for free and open access by the Physics at CORE Scholar. It has been accepted for inclusion in Physics Faculty Publications by an authorized administrator of CORE Scholar. For more information, please contact library-corescholar@wright.edu. 
Authors

David C. Look, D. C. Reynolds, C. W. Litton, R. L. Jones, D. B. Eason, and G. Cantwell 


\title{
Characterization of homoepitaxial $p$-type ZnO grown by molecular beam epitaxy
}

\author{
D. C. Look ${ }^{\text {a) }}$ and D. C. Reynolds \\ Materials and Manufacturing Directorate, Air Force Research Laboratory, Wright-Patterson Air Force \\ Base, Ohio 45433 and Semiconductor Research Center, Wright State University, Dayton, Ohio 45435 \\ C. W. Litton and R. L. Jones \\ Materials and Manufacturing Directorate, Air Force Research Laboratory, Wright-Patterson Air Force \\ Base, Ohio 45433 \\ D. B. Eason and G. Cantwell \\ Eagle-Picher Technologies, L.L.C., 200 BJ Tunnell Boulevard, Miami, Oklahoma 74354
}

(Received 16 May 2002; accepted for publication 10 July 2002)

\begin{abstract}
An N-doped, $p$-type $\mathrm{ZnO}$ layer has been grown by molecular beam epitaxy on an Li-diffused, bulk, semi-insulating $\mathrm{ZnO}$ substrate. Hall-effect and conductivity measurements on the layer give: resistivity $=4 \times 10^{1} \Omega \mathrm{cm}$; hole mobility $=2 \mathrm{~cm}^{2} / \mathrm{V} \mathrm{s}$; and hole concentration $=9 \times 10^{16} \mathrm{~cm}^{-3}$. Photoluminescence measurements in this N-doped layer show a much stronger peak near $3.32 \mathrm{eV}$ (probably due to neutral acceptor bound excitons), than at $3.36 \mathrm{eV}$ (neutral donor bound excitons), whereas the opposite is true in undoped $\mathrm{ZnO}$. Calibrated, secondary-ion mass spectroscopy measurements show an $\mathrm{N}$ surface concentration of about $10^{19} \mathrm{~cm}^{-3}$ in the $\mathrm{N}$-doped sample, but only about $10^{17} \mathrm{~cm}^{-3}$ in the undoped sample. (C) 2002 American Institute of Physics.
\end{abstract}

[DOI: $10.1063 / 1.1504875]$

The need for blue and UV solid-state emitters and detectors has propelled the investigation of several wide-band-gap semiconducting materials in recent years. Commercial applications include blue lasers for CD-ROM and DVD memories, and laser printers, while military applications include blue light-emitting diodes for non-line-of-sight communication transceivers. Most of the materials development for these applications has centered around $\mathrm{GaN}$ (band gap: 3.5 $\mathrm{eV}$ at $2 \mathrm{~K}), \mathrm{ZnSe}(2.9 \mathrm{eV})$, and $6 \mathrm{H}-\mathrm{SiC}(3.0 \mathrm{eV})$, with $\mathrm{GaN}$ and $\mathrm{GaN}$-based alloys emerging as the clear winners, because $\mathrm{SiC}$ does not produce a very bright emitter, and $\mathrm{ZnSe}$ is subject to defect formation under high current drive. However, another II-VI compound, $\mathrm{ZnO}$, is known to be the brightest emitter of all, because its excitons have a $60 \mathrm{meV}$ binding energy, as compared with $26 \mathrm{meV}$ for $\mathrm{GaN}$, and 20 $\mathrm{meV}$ for $\mathrm{ZnSe}$. $\mathrm{ZnO}$ also has other major advantages, such as the availability of large-area substrates, the amenability to wet chemical etching, a high radiation resistance, and relatively low materials costs. ${ }^{1,2}$ However, $\mathrm{ZnO}$ has suffered from one major disadvantage: the lack of good, reproducible, $p$-type material. There are several papers on the growth of $p$-type $\mathrm{ZnO}$ in the recent literature $;^{3-7}$ however, many of them report unrealistically high hole mobilities and hole concentrations. Theoretical treatments of this important subject have also appeared. ${ }^{8-12}$

In this work, we show that reproducible, N-doped, $p$-type $\mathrm{ZnO}$ can be grown by molecular beam epitaxy (MBE) on $\mathrm{ZnO}$ substrates, ${ }^{13,14}$ and that the electrical properties are consistent with modeling and with photoluminescence data. This advancement immediately opens the door to $p-n$ ho-

a) Author to whom correspondence should be addressed; corresponding address: Semiconductor Research Center, Wright State University, Dayton, $\mathrm{OH} 45435$; electronic mail: david.look@wpafb.af.mil mojunctions based on $\mathrm{ZnO}$ materials. Heterojunctions and quantum wells can also be fabricated by using $\mathrm{MgZnO}$ and $\mathrm{CdZnO}$ as the wide-gap and narrow-gap materials, respectively. ${ }^{15-17}$

The homoepitaxial $\mathrm{ZnO}$ thin films were grown by EaglePicher Technologies, LLC (Miami, OK) in a custom-built MBE system that includes extensive cryogenic shrouding and additional cryopumping. The substrates were $10 \mathrm{~mm}$ $\times 10 \mathrm{~mm} \times 0.5 \mathrm{~mm}$ pieces cut from $c$-plane wafers, which themselves were sliced from bulk, 2-inch-diam $\mathrm{ZnO}$ ingots grown by Eagle-Picher using a seeded chemical vapor transport (SCVT) process. ${ }^{18}$ Typical donor and acceptor concentrations were $1 \times 10^{17}$ and $2 \times 10^{15} \mathrm{~cm}^{-3}$, respectively. ${ }^{19}$ Pure $(99.99995 \%) \mathrm{Zn}$ was supplied by means of a solidsource dual-zone effusion cell, and $\mathrm{O}$ and $\mathrm{N}$ were obtained from research-grade $\mathrm{O}_{2}$ and $\mathrm{N}_{2}$, respectively, flowing through an Oxford Applied Research rf plasma source, operated at a power of $350 \mathrm{~W}$. Most of the films were grown on chemomechanically polished Zn (0001) faces. The substrate temperature during growth was varied from 450 to $700{ }^{\circ} \mathrm{C}$, with $525^{\circ} \mathrm{C}$ being used for the layer discussed in this paper.

For $p$-type doping of the films, a flux of $\mathrm{N}_{2}$ gas was added to the $\mathrm{O}_{2}$ gas flow in the rf plasma source. The level of $\mathrm{N}_{2}$ was approximately 10-100 times less than the level of $\mathrm{O}_{2}$. The $p$-type films were grown on Li-doped, semiinsulating $\mathrm{ZnO}$ substrates ${ }^{20}$ in order to be able to perform Hall-effect measurements without influence from substrate conduction. It is well known that $\mathrm{N}$ acts as a shallow acceptor in $\mathrm{ZnSe}$ and $\mathrm{ZnS},{ }^{21}$ and it has also been employed in some of the other attempts to grow $p$-type $\mathrm{ZnO} .^{3,5,6}$ Typical film thicknesses were 1-2 $\mu \mathrm{m}$, with the sample discussed here having a value of $1.9 \mu \mathrm{m}$.

Hall-effect measurements were carried out in the van der Pauw configuration, by using a direct current of $3 \mu \mathrm{A}$, and a 


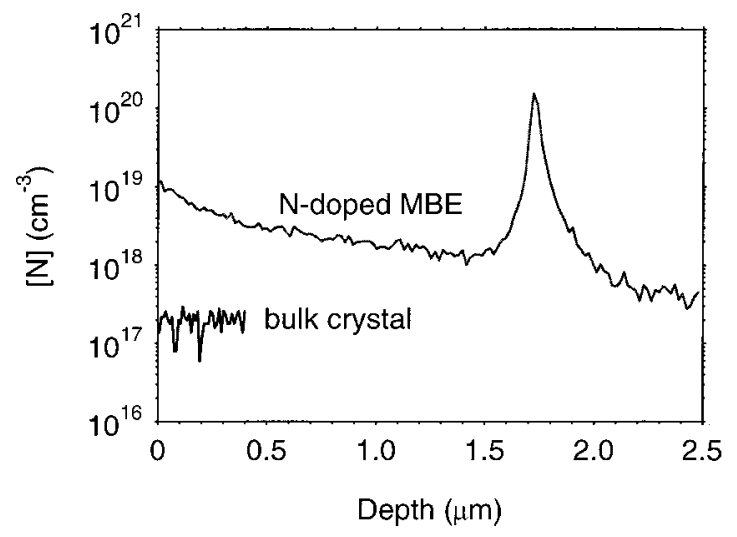

FIG. 1. Secondary ion mass spectroscopy measurements of the $\mathrm{N}$ concentration in two $\mathrm{ZnO}$ samples, one undoped, and the other, N-doped.

magnetic field of $15 \mathrm{kG}$. Data were compiled employing both positive and negative currents and magnetic fields, and the results were averaged in order to compensate for various electromagnetic effects. ${ }^{22}$ Significantly, the Hall coefficient was positive ( $p$-type) for all four current/field combinations, which gives confidence that the layer is truly $p$-type. The averaged results were: resistivity $\rho=4 \times 10^{1} \Omega \mathrm{cm}$; hole mobility $\mu_{p}=2 \mathrm{~cm}^{2} / \mathrm{Vs}$; and hole concentration $p=9$ $\times 10^{16} \mathrm{~cm}^{-3}$. Several other growths have given similar results, and attempts to get larger $p$ and $\mu_{p}$ are now in progress. Below, we demonstrate that the Hall results are quantitatively compatible with analytical and optical data.

Secondary-ion mass spectroscopy (SIMS) determinations of the $\mathrm{N}$ concentrations in similar undoped and $\mathrm{N}$-doped samples are shown in Fig. $1 .^{23}$ The $\mathrm{N}$ concentrations were referenced to an $\mathrm{N}$-implanted $\mathrm{ZnO}$ sample in order to get quantitative information. Absolute accuracy is estimated to be about a factor of 2 but the relative concentrations of the two samples should be more accurate. The bulk sample referred to in Fig. 1 was a substrate similar to the one used for these experiments, except without the $\mathrm{Li}$ diffusion. Note that the $\mathrm{N}$ concentration in the bulk sample is about $1 \times 10^{17} \mathrm{~cm}^{-3}$, while the surface concentration of $\mathrm{N}$ in the epitaxial layer is about two orders of magnitude higher. Also, there appears to be a large $\mathrm{N}$ segregation at the substrate/epilayer interface, with the caveat that SIMS measurements sometimes are subject to artifacts at surfaces and interfaces. In any case, it is clear that the layer is doped with $\mathrm{N}$, as intended. Of course, SIMS cannot distinguish between the various possible lattice locations for the impurity, but the Hall-effect results are consistent only with $\mathrm{N}$ occupying $\mathrm{O}$ sites, as acceptors.

Low-temperature $(4 \mathrm{~K})$ photoluminescence $(\mathrm{PL})$ results for bulk, undoped samples, and MBE-grown, N-doped layers, are compared in Fig. 2. High-quality bulk $\mathrm{ZnO}$ is typically dominated by a series of sharp lines, probably due to bound excitons associated with neutral donors ${ }^{24}$ or very shallow neutral acceptors. ${ }^{25}$ In the present case, the strongest of these lines is at $3.3629 \mathrm{eV}$, with somewhat weaker lines at $3.3598,3.3606$, and 3.3568, in order of intensity. Phonon replicas of these lines are seen near $3.29 \mathrm{eV}$. The $3.3629 \mathrm{eV}$ line has a two-electron satellite (TES) feature at $3.3332 \mathrm{eV}$, and thus is unambiguously a donor-bound exciton $\left(D^{0} X\right),{ }^{26,27}$ associated with a donor at $40 \mathrm{meV}$. The 3.3568

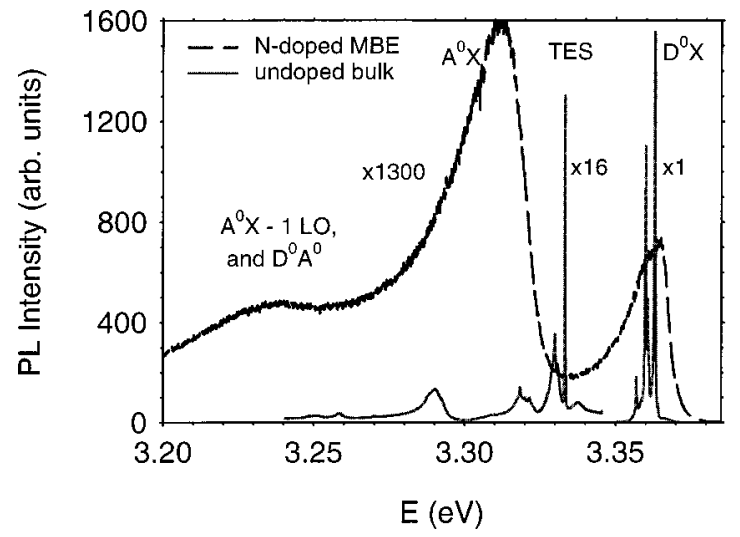

FIG. 2. PL spectra, at $2 \mathrm{~K}$, for two $\mathrm{ZnO}$ samples, an undoped bulk sample, and an N-doped, MBE-grown epitaxial layer.

$\mathrm{eV}$ line has earlier been classified as an acceptor-bound exciton $\left(A^{0} X\right)$, associated with an acceptor at $79 \mathrm{meV} .^{25}$ This acceptor is thought to be a complex center because it seems too shallow for a simple, substitutional acceptor. ${ }^{25}$ Another sharp, excitonic-type line falls at $3.318 \mathrm{eV}$, and if we compare with the $3.3568 \mathrm{eV}$ line (evidently due to a $79 \mathrm{meV}$ acceptor $^{25}$ ), and apply Haynes' Rule, the $3.318 \mathrm{eV}$ line should correspond to an acceptor at about $240 \mathrm{meV}$. However, there is no strong evidence that Haynes' Rule even applies in $\mathrm{ZnO}$, expecially for acceptors. Note that the weaker nature of the $A^{0} X$ lines in undoped SVCT $\mathrm{ZnO}$ is expected, because donor and acceptor concentrations in this material are about $1 \times 10^{17}$ and $2 \times 10^{15} \mathrm{~cm}^{-3}$, respectively. ${ }^{19}$

In comparing the undoped and N-doped samples (Fig. 2 ), the most obvious difference is that the latter has a huge line at $3.315 \mathrm{eV}$, near the "deep" $A^{0} X$ line at $3.318 \mathrm{eV}$ in the undoped sample, and a small line in the $D^{0} X$ region. The simplest explanation for the $3.315 \mathrm{eV}$ feature is that it is an $A^{0} X$ line associated with $\mathrm{N}_{\mathrm{O}}$. Its dominance over the $D^{0} X$ feature is expected from the large number of $\mathrm{N}_{\mathrm{O}}$ centers (Fig. 1 ), and the fact that there are fewer neutral donors (none, in the dark) if the Fermi level is near the acceptor level. Of course, it is also possible that the donor concentration itself has somehow been reduced during the MBE growth, but we have no evidence for this. In fact, it is probable that the only change in the donors is that they are more likely to be close to acceptors, because of the high $\mathrm{N}$ concentration, and thus will contribute to emission through a $D^{0} A^{0}$ process, rather than an excitonic process. The position of the $A^{0} X$ line in the $\mathrm{N}$-doped sample is a little below that in the undoped sample, but, interestingly, this is exactly what is seen in both $\mathrm{ZnSe}$ and $\mathrm{ZnS}$ doped with $\mathrm{N}^{21}$

The broad line centered at $3.238 \mathrm{eV}$ in the $\mathrm{N}$-doped sample is probably composed of two emissions: (1) an LOphonon replica of $A^{0} X$ and (2) $D^{0} A^{0}$ recombination. The $D^{0} A^{0}$ energy for a given pair will be given by $E_{D A}=E_{G}$ $-E_{D}-E_{A}+e^{2} / 4 \pi \varepsilon r$, where $E_{G}, E_{D}$, and $E_{A}$ are the band gap, donor, and acceptor energies, respectively, $\varepsilon$ is the dielectric constant, and $r$ is the pair separation. The average coulomb energy $\Delta E=e^{2} / 4 \pi \varepsilon\langle r\rangle$ can be very roughly estimated by letting $\langle r\rangle \sim\left(3 / 4 \pi N_{A}\right)^{1 / 3}$, with $N_{A}$ $\sim 10^{18}-10^{19} \mathrm{~cm}^{-3}$, giving $\Delta E \sim 0.03-0.06 \mathrm{eV}$. At $2 \mathrm{~K}$, the band gap is $3.437 \mathrm{eV}$, and the donor energy is known to be 
about $60 \mathrm{meV}^{2,24}$ Thus, $E_{A}=3.437-3.238-0.060+\Delta E$ $\approx 0.17-0.20 \mathrm{eV}$. The high end of this range is comparable to the optical (PL) value of $224 \mathrm{meV}$ found for the acceptor in lightly Mg-doped GaN. ${ }^{28}$ This is not unexpected, since the band structures of $\mathrm{GaN}$ and $\mathrm{ZnO}$ are very similar. Interestingly, the low end of our range, $0.17 \mathrm{eV}$, is comparable to the electrical (Hall) value of $E_{A}$ in $p$-type GaN. ${ }^{29}$ Along with the similarities in the PL spectra of $p$-type $\mathrm{ZnO}$ and $p$-type $\mathrm{GaN}$, there is an interesting difference: the $A^{0} X$ emission is much stronger than the $D^{0} A^{0}$ emission in heavily $\mathrm{N}$-doped $\mathrm{ZnO}$ (Fig. 2), but the opposite is true in heavily Mg-doped GaN. ${ }^{30}$ This fact supports the contention that the emission in $\mathrm{ZnO}-$ based photonic devices is more likely to be driven by excitonic processes than that in $\mathrm{GaN}$-based devices.

To compare the electrical properties of $p$-type $\mathrm{ZnO}$ and $\mathrm{GaN}$, we note that, for Mg-doped, $p$-type $\mathrm{GaN}$, typical values of $\mu_{p}$ and $p$ are about $5 \mathrm{~cm}^{2} / \mathrm{V} \mathrm{s}$ and $1 \times 10^{17} \mathrm{~cm}^{-3}$, respectively, ${ }^{29,31}$ close to our measured values for $\mathrm{N}$-doped, $p$-type $\mathrm{ZnO}$. Moreover, any reported values of $\mu_{p}$ and $p$ much higher than these in GaN should be viewed with some caution, as will be discussed later. To be more quantitative, the hole concentration, in a nondegenerate, single-donor/ single-acceptor model, will be given by ${ }^{22}$

$$
p=\frac{1}{2}\left(\phi_{A}+N_{D}\right)\left\{\left[1+\frac{4 \phi_{A}\left(N_{A}-N_{D}\right)}{\left(\phi_{A}+N_{D}\right)^{2}}\right]^{1 / 2}-1\right\}
$$

where $N_{A}$ and $N_{D}$ are the acceptor and donor concentrations, respectively, and $\phi_{A}=\left(g_{A 1} / g_{A 0}\right) N_{V}^{\prime} T^{3 / 2} \exp \left(\alpha_{A} / k\right)$ $\times \exp \left(-E_{A 0} / k T\right)$. Here, $g_{A 0}$ and $g_{A 1}$ are the unoccupied and occupied state degeneracies, respectively, $N_{V}^{\prime}$ is the effective density of states at $1 \mathrm{~K}, T$ is the absolute temperature, and $\alpha_{A}$ is a linear temperature coefficient defined by $E_{A}=E_{A 0}$ $-\alpha_{A} T$. For $\mathrm{N}$ on an $\mathrm{O}$ site, we would expect that $g_{A 0}=4$ and $g_{A 1}=1$. If we assume an effective hole mass of $m_{p}$ $=1 m_{0}$, then $N_{V}^{\prime}=4.94 \times 10^{15} \mathrm{~cm}^{-3} \mathrm{~K}^{-3 / 2}$, and if we assume that $E_{A}=170 \mathrm{meV}$, as estimated above, then $\phi_{A}=9$ $\times 10^{15} \mathrm{~cm}^{-3}$. Since, from the SIMS data, $[N] \approx N_{A} \geqslant 5$ $\times 10^{18} \mathrm{~cm}^{-3} \gg \phi_{A}$, we can approximate Eq. (1) by $p$ $=\left(N_{A} / N_{D}-1\right) \phi_{A}$. Then, our value of $p=9 \times 10^{16} \mathrm{~cm}^{-3}$ would be consistent with a compensation ratio $N_{D} / N_{A}$ $\approx 0.1$, a reasonable value, and within the range of compensation ratios determined in Mg-doped $p$-type GaN. ${ }^{29,31}$ It is interesting that, for $\mathrm{ZnO}$ in this concentration regime, the ratio $N_{A} / N_{D}$ is more important than $N_{A}$ itself for obtaining a high value of $p$. Of course, for high mobility, both $N_{A}$ and $N_{D}$ should be small.

There have been several reports of $p$-type $\mathrm{ZnO}$ recently. Minegishi et al. ${ }^{3}$ obtained $\mu_{p}=12 \mathrm{~cm}^{2} / \mathrm{Vs}$ and $p=1.5$ $\times 10^{16} \mathrm{~cm}^{-3}$, and Butkhuzi et al. ${ }^{7}$ obtained $\mu_{p}$ $=23 \mathrm{~cm}^{2} / \mathrm{V} \mathrm{s}$ and $p=4 \times 10^{14} \mathrm{~cm}^{-3}$; these values seem reasonable, according to the above arguments. However, most of the other workers ${ }^{4-6}$ have obtained values of $p$ in the $10^{18}-10^{21} \mathrm{~cm}^{-3}$ range. It is difficult to understand how such high hole concentrations could result from a $>150 \mathrm{meV}$ acceptor. In this regard, it should be pointed out that an artificially low Hall voltage, which can result from a number of causes, will lead to artificially high values of $p$, and low values of $\mu_{p}$. Thus, great care must be taken in the Halleffect measurements and their interpretation.
In summary, we have produced homoepitaxial $\mathrm{N}$-doped, $p$-type $\mathrm{ZnO}$ by MBE. The values of $\mu_{p}$ and $p$ from Halleffect measurements are reasonable and quantitatively consistent with modeling, with SIMS results, with PL spectra, and with Hall and PL results for $p$-type GaN and other $p$-type II-VI compounds. These results suggest that a $p-n$ homojunction can be produced in $\mathrm{ZnO}$.

We wish to thank T.A. Cooper for the Hall-effect measurements, and J.E. Hoelscher and W. Rice for the PL measurements. Two authors (D. C. L. and D. C. R.) were supported by U.S. Air Force Contract No. F33615-00-C-5402.

${ }^{1}$ Y. Chen, D. Bagnall, and T. Yao, Mater. Sci. Eng., B 75, 190 (2000).

${ }^{2}$ D. C. Look, Mater. Sci. Eng., B 80, 383 (2001).

${ }^{3}$ K. Minegishi, Y. Koiwai, and K. Kikuchi, Jpn. J. Appl. Phys. 36, L1453 (1997).

${ }^{4}$ Y. R. Ryu, S. Zhu, D. C. Look, J. M. Wrobel, H. M. Joeng, and H. W. White, J. Cryst. Growth 216, 330 (2000).

${ }^{5}$ M. Joseph, H. Tabata, H. Saeki, K. Ueda, and T. Kawai, Physica B 302303, 140 (2001).

${ }^{6}$ X. -L. Guo, H. Tabata, and T. Kawai, J. Cryst. Growth 223, 135 (2001).

${ }^{7}$ T. V. Butkhuzi, M. M. Sharvashidze, N. M. Gamkrelidze, Kh. V. Gelovani, T. G. Khulordava, N. P. Kekelidze, and E. E. Kekelidze, Semicond. Sci. Technol. 16, 575 (2001).

${ }^{8}$ T. Yamamoto and H. Katayama-Yoshida, Jpn. J. Appl. Phys. 38, L166 (1999).

${ }^{9}$ Y. Yan, S. B. Zhang, and S. T. Pantelides, Phys. Rev. Lett. 86, 5723 (2001).

${ }^{10}$ S. B. Zhang, S. -H. Wei, and A. Zunger, Phys. Rev. B 63, 075205 (2001).

${ }^{11}$ F. Oba, S. R. Nishitani, S. Isotani, H. Adachi, and I. Tanaka, J. Appl. Phys. 90, 824 (2001).

${ }^{12}$ E. -C. Lee, Y. -S. Kim, Y.- G. Jin, and K. J. Chang, Phys. Rev. B 64, 085120 (2001).

${ }^{13}$ D. B. Eason and G. Cantwell, in Proceedings of the 2002 International Conference on Solid State Devices and Material (in press).

${ }^{14}$ D. B. Eason and G. Cantwell, Compd. Semicord. 8, 15 (2002).

${ }^{15}$ A. Ohtomo, R. Shiroki, I. Ohkubo, H. Koinuma, and M. Kawasaki, Appl. Phys. Lett. 75, 4088 (1999).

${ }^{16}$ C. W. Teng, J. F. Muth, Ü. Özgür, M. J. Bergmann, H. O. Everitt, A. K. Sharma, C. Jin, and J. Narayan, Appl. Phys. Lett. 76, 979 (2000).

${ }^{17}$ T. Makino, Y. Segawa, M. Kawasaki, A. Ohtomo, R. Shiroki, K. Tamura, T. Yasuda, and H. Koinuma, Appl. Phys. Lett. 78, 1237 (2001).

${ }^{18}$ Eagle-Picher Technologies, 200 BJ Tunnell Blvd., Miami, OK 74354.

${ }^{19}$ D. C. Look, D. C. Reynolds, J. R. Sizelove, R. L. Jones, C. W. Litton, G. Cantwell, and W. C. Harsch, Solid State Commun. 105, 399 (1998).

${ }^{20}$ A. Valentini, F. Quaranta, M. Rossi, and G. Battaglin, J. Vac. Sci. Technol. A 9, 286 (1991)

${ }^{21}$ L. Svob, C. Thiandoume, A. Lusson, M. Bouanani, Y. Marfaing, and O. Gorochov, Appl. Phys. Lett. 76, 1695 (2000).

${ }^{22}$ D. C. Look, Electrical Characterization of GaAs Materials and Devices (Wiley, New York, 1989).

${ }^{23}$ Evans East, 104 Windsor Center, Suite 101, East Windsor, NJ 08520.

${ }^{24}$ D. C. Reynolds, D. C. Look, B. Jogai, C. W. Litton, T. C. Collins, W. Harsch, and G. Cantwell, Phys. Rev. B 57, 12151 (1998).

${ }^{25}$ J. Gutowski, N. Presser, and I. Broser, Phys. Rev. B 38, 9746 (1988).

${ }^{26}$ K. Thonke, Th. Gruber, N. Teofilov, R. Schönfelder, A. Waag, and R. Sauer, Physica B 308-310, 945 (2001).

${ }^{27}$ D. C. Look, R. L. Jones, J. R. Sizelove, N. Y. Garces, N. C. Giles, and L. E. Halliburton, Phys. Status Solidi A (in press).

${ }^{28}$ B. J. Skromme and G. L. Martinez, MRS Internet J. Semicond. Res. 5S1, W9.8 (2000).

${ }^{29}$ A. K. Rice and K. J. Malloy, J. Appl. Phys. 89, 2816 (2001).

${ }^{30}$ M. W. Bayerl, M. S. Brandt, O. Ambacher, M. Stutzmann, E. R. Glaser, R. L. Henry, A. E. Wickenden, D. D. Koleske, T. Suski, I. Grzegory, and S. Porowski, Phys. Rev. B 63, 125203 (2001).

${ }^{31}$ U. Kaufmann, P. Schlotter, H. Obloh, K. Köhler, and M. Maier, Phys. Rev. B 62, 10867 (2000). 